\title{
Relationship of Plasma Insulin Levels to the Incidence of Myocardial Infarction and Coronary Heart Disease Mortality in a Middle-aged Population
}

\author{
P. Ducimetiere, E. Eschwege, L. Papoz, J. L. Richard, J. R. Claude, and G. Rosselin \\ Groupe d'Etude sur l'Epidémiologie de l'Athérosclérose, Paris, France
}

Summary. The possible role of plasma insulin levels as a risk factor of coronary heart disease has been studied in a population of 7246 non diabetic, working men, aged 43-54 years, initially free from heart disease, and followed for 63 months on average. 128 new coronary heart disease events (non fatal myocardial infarction and coronary related deaths) were detected during this period. The annual risk is analysed by a multivariate model including age, serum cholesterol and triglycerides, blood pressure, smoking, obesity, plasma glucose and insulin fasting and 2 hours after a $75 \mathrm{~g}$ oral glucose load. It is shown that the fasting plasma insulin level and the fasting insulin-glucose ratio are positively associated with risk independent of the other factors. The same variables, 2 hours after the glucose load are also positively associated with risk but their contributions are not significant in the multivariate analysis. It is concluded that high insulin levels may constitute an independent risk factor for coronary heart disease complications in middle aged non diabetic men.

Key words: Epidemiology, coronary heart disease risk factors, oral glucose tolerance test, plasma insulin.

It has been long recognized that diabetes mellitus leads to various clinical manifestations of atherosclerosis including coronary heart disease (CHD). Many retrospective and prospective studies [1] have confirmed this. Investigation of a possible link between so-called chemical diabetes as defined by glucose intolerance alone and the development of $\mathrm{CHD}$ have been extensive. However, the results remain unclear and controversial mainly due to the lack of adequate incidence data [2].
The hypothesis that high circulating insulin levels may be associated with the development of $\mathrm{CHD}$ has been supported in the past by experimental and clinical evidence. Stout $[3,4,5]$ suggested two possible non exclusive mechanisms: a direct effect on arterial metabolism or through an effect on lipid metabolism.

The relationships of plasma insulin levels, fasting and two hours post oral glucose load to the onset of myocardial infarction and CHD related deaths as observed in the non diabetic middle aged males of the Paris Prospective Study have been investigated in the present work. In assessing these relationships, multivariate adjustment of classical CHD risk factors, particularly plasma lipids, has been systematically carried out.

\section{Material and Methods}

The general aims, methodology and first results of the Paris Prospective Study have been published [6] and only relevant data are given here.

One year after entry into the study, 7535 men aged 43-54 years, working in the Paris Civil Service attended the first annual follow-up session (1968-1973). This included a cardiovascular clinical examination, medical history questionnaire and biological measurements. At that time, 150 cases of coronary heart disease were diagnosed which represented $2 \%$ of the population. These cases have been excluded from the follow-up analysis.

Systolic blood pressure was measured in a sitting position during the clinical examination by a standard cuff technique. A body mass index (BMI) was computed from height $(\mathrm{H})$ in metres and weight $(\mathrm{W})$ in $\mathrm{kg}$ as $\mathrm{BMI}=1000\left[\log _{10}\left(\mathrm{~W} / \mathrm{H}^{2}\right)-1\right]$ [7]. Cigarette consumption was measured by the mean daily consumption during the preceeding 5 years estimated from a questionnaire about smoking habits during the life of the subject. After an overnight fast venous blood was taken for analysis of cholesterol [8] and triglycerides [9], plasma glucose $[10]\left(\mathrm{G}_{0}\right)$ and insulin [11] $\left(\mathrm{I}_{0}\right)$. A $75 \mathrm{~g}$ oral glucose tolerance test was performed [12] with measurement of plasma glucose $\left(\mathrm{G}_{2}\right)$ and insulin $\left(\mathrm{I}_{2}\right)$ two hours after the load.

Among the 7385 subjects initially free from $\mathrm{CHD}$, followed-up for 63 months on average, 73 cases of myocardial infarction ascer- 
Table 1. Coronary heart disease risk factors and plasma glucose and insulin in 7246 non diabetic men. Results are stated as mean, and mean $\pm 2 \mathrm{SD}$

\begin{tabular}{|c|c|c|c|c|c|c|c|c|c|}
\hline \multirow[t]{2}{*}{$\begin{array}{l}\text { Age } \\
\text { (years) }\end{array}$} & \multirow[t]{2}{*}{$\begin{array}{l}\text { Cholesterol } \\
(\mathrm{mg} / \mathrm{dl})\end{array}$} & \multirow[t]{2}{*}{$\begin{array}{l}\text { Systolic BP } \\
(\mathrm{mm} \mathrm{Hg})\end{array}$} & \multirow[t]{2}{*}{$\begin{array}{l}\text { Cigarettes } \\
(\mathrm{n} / \mathrm{d})\end{array}$} & \multirow[t]{2}{*}{$\begin{array}{l}\text { Body mass } \\
\text { index }\end{array}$} & \multirow[t]{2}{*}{$\begin{array}{l}\text { Triglycerides }{ }^{\mathrm{b}} \\
(\mathrm{mg} / \mathrm{dl})\end{array}$} & \multicolumn{2}{|c|}{$\begin{array}{l}\text { Plasma glucose }{ }^{b} \\
(\mathrm{mg} / \mathrm{dl})\end{array}$} & \multicolumn{2}{|c|}{$\begin{array}{l}\text { Plasma insulin } \\
(\mathrm{mU} / \mathrm{ml})\end{array}$} \\
\hline & & & & & & 0 & $2 \mathrm{~h}$ & 0 & $2 \mathrm{~h}$ \\
\hline $\begin{array}{l}49 \\
(45-53)\end{array}$ & $\begin{array}{l}217 \\
(133-301)\end{array}$ & $\begin{array}{l}144 \\
(101-186)\end{array}$ & $\begin{array}{l}9 \\
(0-28)\end{array}$ & $\begin{array}{l}410 \\
(302-518)\end{array}$ & $\begin{array}{l}109 \\
(38-314)\end{array}$ & $\begin{array}{l}101 \\
(71-144)\end{array}$ & $\begin{array}{l}99 \\
(50-194)\end{array}$ & $\begin{array}{l}10 \\
(3-38)\end{array}$ & $\begin{array}{l}32 \\
(6-172)\end{array}$ \\
\hline
\end{tabular}

$0=$ at fasting, $2 \mathrm{~h}=2 \mathrm{~h}$ post oral glucose load

${ }^{a}$ Body mass index is expressed by 1000 [ $\log _{10}$ (weight $\mathrm{kg} / \mathrm{height}{ }^{2} \mathrm{~m}$ )-1]

${ }^{b} \mathrm{~m}$ and $\mathrm{m} \pm 2 \mathrm{SD}$ are computed in natural logarithm values, then transformed into original units

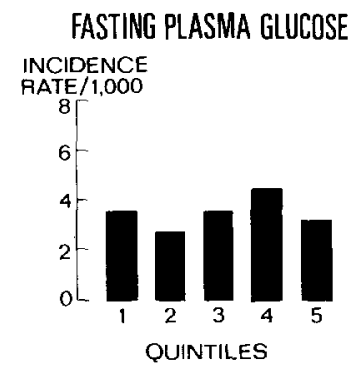

FASTING PLASMA INSULIN

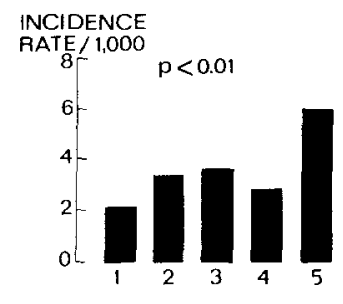

QUINTILES

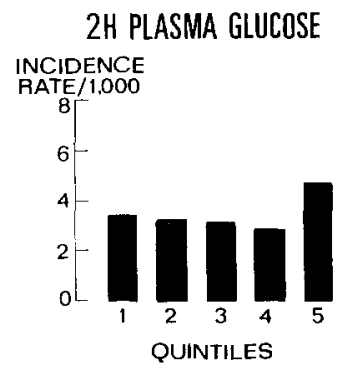

2H PLASMA INSULIN

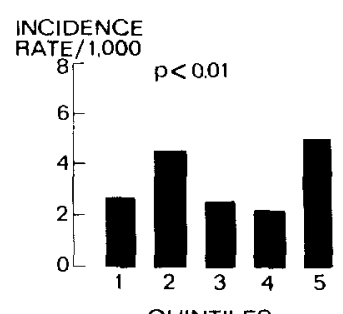

QUINTILES

Fig. 1. Mean annual incidenve of $\mathrm{CHD}$ complications by quintiles of plasma glucose (G) and insulin (I) levels, fasting (0) and 2 hours after glucose load (2). Quintiles limits are defined as follow's:

$\mathrm{G}_{0} \mathrm{mg} / \mathrm{dl}: \leqslant 92,93-98,99-103,104-110, \geqslant 111$;

$\mathrm{G}_{2} \mathrm{mg} / \mathrm{dl}: \leqslant 77,78-90,91-105,106-125, \geqslant 126$;

$\mathrm{I}_{0} \mathrm{mU} / \mathrm{l}: \leqslant 4,5-7,8-10,11-15, \geqslant 16$;

$\mathrm{I}_{2} \mathrm{mU} / \mathrm{l}: \leqslant 16,17-27,28-41,42-61, \geqslant 62$.

Comparison of observed and expected number of events among quintiles (chi-square test)

tained by hospital data and 59 CHD deaths, mostly sudden deaths were detected as of 1st January 1977. The mean annual incidence of overall CHD complications is 3.4/1000. Among 139 men with overt diabetes as defined by existing treatment for diabetes by drugs or diet, 4 new $\mathrm{CHD}$ cases were observed. All diabetic cases have been excluded from the following results.

\section{Statistical Techniques}

Multivariate analysis of the relationship between annual CHD incidence rates and different variables was performed by an exponential survival model with

covariates which allows for unequal follow-up durations $[13,14]$. The outline of the model is given in the Appendix.

\section{Results}

The mean and the mean \pm 2SD interval for each variable analysed are given Table 1 . Taking into account the "heavy tailed" distribution of serum triglycerides, plasma glucose and insulin values, these data were transformed by natural logarithms prior to analysis.

The annual incidence per 1000 of CHD complications is shown in Figure 1 according to quintiles of glucose and insulin levels, both fasting and two hours after glucose load. No clear-cut relationship of the CHD risk with any of the four variables is evident. The comparison (by a chi-square test) of observed and expected numbers of complications in each group showed no significant difference among $\mathrm{G}_{0}$ and $\mathrm{G}_{2}$ quintiles. No significant higher $\mathrm{CHD}$ incidence was detected for individuals with blood glucose above the 95 th percentile $\left(120 \mathrm{mg} / 100 \mathrm{ml}\right.$ for $\mathrm{G}_{0}$ and $162 \mathrm{mg} / 100 \mathrm{ml}$ for $\mathrm{G}_{2}$ ) as the mean annual incidence rate was respectively $4.7 / 1000$ ( 8 events) and 3.3/1000 ( 7 events) in these groups. However, significant differences of incidence were observed among $I_{0}$ and $I_{2}$ quintiles $(p<0.01)$. In both cases the highest rate was observed in the top quintile.

The estimate of CHD complications risk was based on classical factors which included the variables cholesterol, systolic BP and cigarette consumption as significant predictors (Table 2, left side). Taking into account the narrow range of age in the population, its coefficient was not significantly different from 0 . Coefficients for triglycerides (taken as $\ln$ triglycerides) and body mass index were not significant when added to the previous variables as shown in Table 2 (right hand side). 
Table 2. Coronary heart disease multivariate risk function including the four classical risk factors (left side) and then body mass index and triglycerides level (right side)

\begin{tabular}{lllllll}
\hline Variable & Coeff. $\mathrm{b}^{\mathrm{a}}$ & $\mathrm{t}$ value & $\mathrm{P}$ & Coeff. $\mathrm{b}^{\mathrm{a}}$ & $\mathrm{t}$ value & $\mathrm{P}$ \\
\hline Age (years) & 0.039 & 0.78 & $\mathrm{NS}$ & 0.041 & 0.80 & $\mathrm{NS}$ \\
Cholesterol (mg/dl) & 0.004 & 3.51 & $<0.001$ & 0.004 & 2.81 & $<0.01$ \\
Systolic BP (mm Hg) & 0.016 & 4.82 & $<0.001$ & 0.015 & 4.27 & $<0.001$ \\
Cigarettes (n/d) & 0.040 & 5.56 & $<0.001$ & 0.041 & 5.66 & $<0.001$ \\
Body mass index & & & & 0.000 & 0.15 & $\mathrm{NS}$ \\
Triglycerides ${ }^{\mathrm{b}}(\mathrm{mg} / \mathrm{dl})$ & & & & 0.208 & 1.23 & NS \\
\hline
\end{tabular}

${ }^{a}$ Coefficient of each variable in the multivariate expression of risk (see Appendix)

${ }^{b}$ In value

Table 3. Coronary heart disease multivariate risk function including successively fasting (left side) and 2 h post load (right side) plasma glucose $(\mathrm{G})$ and insulin $(\mathrm{I})$ levels

\begin{tabular}{|c|c|c|c|c|c|c|}
\hline Variable & Coeff. $b^{a}$ & $\mathrm{t}$ value & $\mathbf{P}$ & Coeff. $b^{a}$ & $\mathrm{t}$ value & $\mathrm{P}$ \\
\hline Cholesterol (mg/dl) & 0.005 & 3.52 & $<0.001$ & 0.004 & 3.30 & $<0.001$ \\
\hline Systolic BP (mm Hg) & 0.015 & 4.12 & $<0.001$ & 0.015 & 4.32 & $<0.001$ \\
\hline Cigarettes $(\mathrm{n} / \mathrm{d})$ & 0.042 & 5.77 & $<0.001$ & 0.044 & 5.90 & $<0.001$ \\
\hline $\mathrm{G}_{0}^{b}(\mathrm{mg} / \mathrm{dl})$ & -1.291 & -1.56 & NS & & & \\
\hline $\mathbf{I}_{0}{ }^{\mathrm{b}}(\mathrm{mU} / \mathrm{l})$ & 0.379 & 2.58 & $<0.01$ & & & \\
\hline $\mathrm{G}_{2}{ }^{\mathrm{b}}(\mathrm{mg} / \mathrm{dl})$ & & & & -0.234 & -0.67 & NS \\
\hline $\mathbf{I}_{2}{ }^{b}(\mathrm{mU} / \mathrm{l})$ & & & & 0.182 & 1.32 & NS \\
\hline
\end{tabular}

a Coefficient of each variable in the multivariate expression of risk (see Appendix)

${ }^{b}$ In value

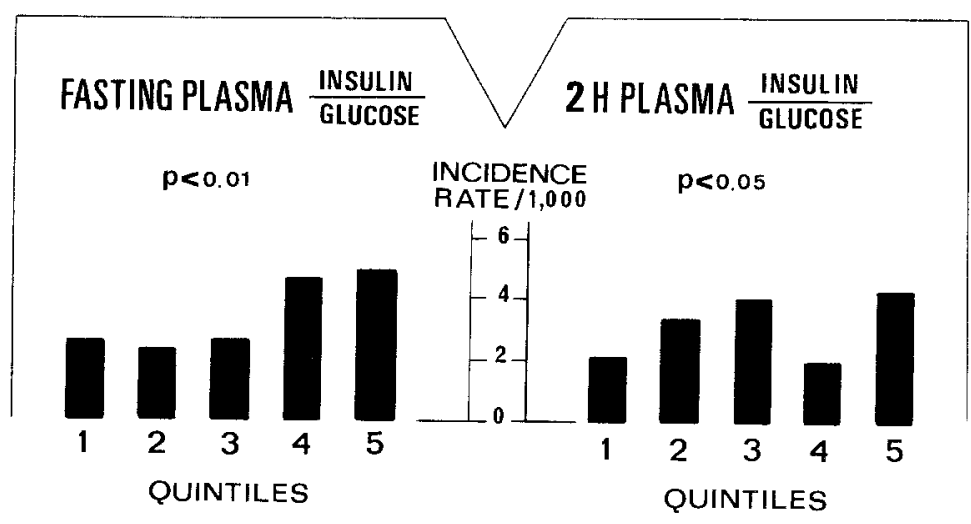

Fig. 2. Mean annual incidence of $\mathrm{CHD}$ complications according to quintiles of fasting $(0)$ and $2 \mathrm{~h}$ after glucose load (2) plasma insulin/glucose ratios (I/G). Quintiles limits are defined as follows:

$\mathrm{I}_{0} / \mathrm{G}_{0} \mathrm{mU} / \mathrm{g}: \leqslant 6,7-9,10-12,13-17, \geqslant 18$; $\mathrm{I}_{2} / \mathrm{G}_{2} \mathrm{mU} / \mathrm{g}: \leqslant 16,17-24,25-34,35-53, \geqslant 54$. Comparison of observed and expected number of events among quintiles (chi-square test)
As a first step, fasting and two hour post glucose load insulin and glucose parameters were introduced independently in the multivariate model for $\mathrm{CHD}$ incidence (Table 3). In both cases, positive coefficients for insulin and negative coefficients for glucose were obtained, but only the $\mathrm{I}_{0}$ coefficient reached statistical significance $(p<0.01)$ while the coefficients for the other risk factors did not show much change. These results suggest that the insulin/glucose ratios may be more strongly associated with risk than insulin values alone, at least when assuming the exponential model for risk dependence.
The annual incidence rate of $\mathrm{CHD}$ complications according to quintiles of $\mathrm{I}_{0} / \mathrm{G}_{0}$ and $\mathrm{I}_{2} / \mathrm{G}_{2}$ is depicted in Figure 2 . It shows a higher CHD risk (multiplied by 1.9) for the last two quintiles of $I_{0} / G_{0}(\geqslant 13 \mathrm{mU} / \mathrm{g})$ without any evident trend below this level. A pattern of consistent increase is not obtained with $\mathrm{I}_{2} / \mathrm{G}_{2}$ but incidence levels among quintiles are significantly different for both variables. Table 4 shows that in the multivariate analysis $I_{0} / G_{0}$ brought a significant independent contribution to the CHD risk estimate (left side). On the other hand, the coefficient of $I_{2} / G_{2}$ introduced in the same condition was not significant. 
Table 4. Coronary heart diesease multivariate risk function including successively fasting (left side) and $2 \mathrm{~h}$ post load (right side) plasma insulin/glucose ratios $(\mathrm{I} / \mathrm{G})$

\begin{tabular}{lllllll}
\hline Variable & Coeff. $b^{\mathrm{a}}$ & $\mathrm{t}$ value & $\mathrm{P}$ & Coeff. $\mathrm{b}^{\mathrm{a}}$ & $\mathrm{t}$ value & $\mathrm{P}$ \\
\hline Cholesterol (mg/dl) & 0.004 & 3.36 & $<0.001$ & 0.004 & 3.28 & $<0.001$ \\
Systolic BP (mm Hg) & 0.014 & 4.09 & $<0.001$ & 0.015 & 4.51 & $<0.001$ \\
Cigarettes $(\mathrm{n} / \mathrm{d})$ & 0.042 & 5.77 & $<0.001$ & 0.043 & 5.90 & $<0.001$ \\
$\mathrm{I}_{0} / \mathrm{G}_{0}{ }^{\mathrm{b}}(\mathrm{mU} / \mathrm{g})$ & 0.331 & 2.39 & $<0.02$ & & & NS \\
$\mathrm{I}_{2} / \mathrm{G}_{2}{ }^{\mathrm{b}}(\mathrm{mU} / \mathrm{g})$ & & & & 0.183 & 1.39 & \\
\hline
\end{tabular}

${ }^{a}$ Coefficient of each variable in the multivariate expression of risk (see Appendix)

${ }^{\mathrm{b}} \ln$ value

In these multivariate analyses, inclusion of body mass index and triglycerides levels, which were positively correlated with glucose and insulin levels in this population [12], did not cause any change in the results.

\section{Discussion}

The relationship of diabetes to the development of coronary heart disease has been a subject of major interest during the last fifteen years: a huge body of facts has been gathered, mostly from retrospective studies comparing diabetics, or patients with $\mathrm{CHD}$, to controls.

The assessment of a relationship between parameters of the glucose metabolism and subsequent CHD complications in asymptomatic populations was an alternative approach. As far as impairment of glucose tolerance in otherwise asymptomatic people may represent "chemical diabetes", could it be considered as an aetiologic factor for CHD? In some studies an excess of CHD risk seems to be present in persons with borderline fasting blood glucose levels and/or glucose intolerance $[15,16]$, but there is no convincing evidence whether or not hyperglycaemia is an independent risk factor.

Recent data from fifteen population studies from the International Collaborative Group [17] failed to indicate a clear-cut continuous independent association of glucose level (fasting or post load) with CHD mortality. The hypothesis of a threshold effect with higher CHD mortality in the extreme 2 or $3 \%$ of the $2 \mathrm{~h}$ post load glucose distribution was raised mainly from data of the Whitehall Study [18] which was the only one to include an adequate number of men in this subgroup. In the preliminary results of the Paris Prospective Study [19], only one CHD death was observed in the 2.5 th percentile and no conclusion could be drawn. However, the present results do not show a significant increase of risk of myocardial infarction and $\mathrm{CHD}$ death which would be confined to the extreme $5 \%$ of the $\mathrm{G}_{0}$ or $\mathrm{G}_{2}$ distribution.
The possibility that hyperinsulinaemia would be involved in the development of the atherosclerotic process and CHD complications in humans was set forth particularly by Stout [5] who presented a series of convincing experimental and clinical arguments. The recent results of the Helsinki Policemen Study $[20,21]$, the Busselton Study [22], and those of the present work produce the first prospective bulk of evidence for this association in asymptomatic middle aged men.

As early as 1965, plasma insulin levels during an oral glucose tolerance test were found to be higher in non diabetic myocardial infarction survivors than in controls $[23,24]$. From that time, numerous retrospective studies have globally verified this fact but detailed results are often at variance, as discussed in [5].

Our finding that a high fasting insulin level $\left(\mathrm{I}_{0}\right)$ is more closely associated with CHD risk than corresponding values two hours after a glucose load $\left(\mathrm{I}_{2}\right)$ is not in accordance with the results of Pyorälä [21]. He found that fasting, $1 \mathrm{~h}$ and $2 \mathrm{~h}$ plasma insulin levels were associated with a 5 year incidence of $\mathrm{CHD}$ death and non fatal myocardial infarction. The $2 \mathrm{~h}$ level appeared, however, a better predictor than the fasting level, and was kept in the multivariate analysis of risk. Welborn [22] observed a significant association of $1 \mathrm{~h}$ insulin level with CHD incidence and CHD mortality in men and, in this last case, it persisted when other risk factors were taken into account. However, the same association was not found among women.

When the insulin and other risk factor levels are kept constant in the multivariate analysis, the negative coefficient for glucose, though non significant, is a striking feature of the present results. This may suggest that in non diabetic middle aged men an excess of insulin for a given glucose level, classically called "insulin resistance" [25], is the key variable for predicting CHD complications. Pyorälä [22] found a non significant but positive coefficient for $2 \mathrm{~h}$ blood glucose when $2 \mathrm{~h}$ insulin was taken into account. The insulin/glucose ratio has been proposed $[26,27]$ as a 
measure of insulin resistance and, accordingly, this variable has been conventionally introduced in the analysis. However, Sorge [28] has already found a higher $\Sigma \mathrm{I} / \Sigma \mathrm{G}$ ratio in subjects with myocardial infarction than in controls (with $I$ and $G$ measured 1 and 2 hours after glucose load), and Santen [29] a higher fasting $I / G$ ratio in diabetics with atherosclerosis compared to diabetics without atherosclerosis.

The inter-relationship of insulinaemia with obesity and hyperlipidaemia in diabetics and non diabetics has been extensively studied [1]. This discussion is beyond the scope of the present work; but whatever mechanisms are involved, highly significant positive correlations have been generally observed between these variables and particularly triglycerides [12]. In each case where a possible link between insulinaemia and $\mathrm{CHD}$ has been evoked, a key role for hypertriglyceridaemia has been suggested. However, there is no consistent epidemiological evidence [30] for the relationship of triglycerides to CHD risk in men when the cholesterol level is controlled. Negative results, as in this study, were obtained in Framingham [31], Göteborg [32] and Helsinki [21]. On the contrary a clear-cut positive relationship was published by Carlson [33] and most evidence cited relies on this work alone, the methodology of which has been criticized [34]. From the present results, it seems unlikely that the CHD risk increase with the insulin level is mediated by corpulence and/or triglycerides. No data is available, however, on the role of other forms of circulating lipids particularly HDL cholesterol, whose importance has recently been stressed once again. At least in women over fifty years of age, diabetes but not triglycerides remained a $\mathrm{CHD}$ risk factor independently of HDL cholesterol in the Framingham Study [32]. Further studies are required to elucidate the role of insulin in the aetiology of CHD in man, but the hypothesis of a direct effect on the atherosclerosis process may be considered from the present evidence.

\section{Appendix}

\section{Exponential Survival Model with Covariates}

During follow-up (5 years on average) the hazard rate for CHD is supposed to be constant (r) for each subject. This assumption is equivalent to stating that the probability that the subject will suffer or die from CHD before the instant $t$ is $1-e^{-r t}$, the classical exponential survival model. The hazard rate $r$ is a function of the covariates $\mathrm{x}_{1}, \mathrm{x}_{2} \ldots$ (age, cholesterol ...) chosen as:

$r=r_{0} \exp \left(b_{1} x_{1}+\ldots+b_{k} x_{k}\right)$
If $\mathrm{N}$ is the total number of subjects, $\mathrm{n}$ the number of new CHD events, $t_{i}$ their time delay before the occurence of the CHD complications and the followup duration for the other subjects, then the ln likelihood of the observations is:

$$
\begin{gathered}
L=n \ln r_{0}+\sum_{i=1}^{i=n}\left(b_{1} x_{1}^{i}+\ldots+b_{k} x_{k}^{i}\right) \\
-r_{0} \sum_{i=1}^{i=N} t_{i} \exp \left(b_{1} x_{1}^{i}+\ldots+b_{k} x_{k}^{i}\right)
\end{gathered}
$$

Maximizing this quantity by an iterative technique gives the estimates and standard errors of $r_{0}$ and $b_{j}$ 's, providing a test of significance of the $b_{j}$ 's by the Student $\mathrm{t}$ test.

Acknowledgements. The Groupe d'Etude sur l'Epidémiologie de l'Athérosclérose, G.R.E.A., 27 rue Lacordaire, F-75 015 Paris (France), includes participation of the "Institut National de la Santé et de la Recherche Médicale - I.N.S.E.R.M." (Unités 169 et 21, Equipe de Cardiologie, Unité 55) and the "Préfecture de Paris" (Laboratoire de Recherche sur la Prévention des Maladies Cardiovasculaires) with grants of "Ministère de la Santé et de la Famille".

\section{References}

1. West KM (1978) Specific morbid effects (complications): atherosclerosis and related disorders. In: West KM (ed) Epidemiology of diabetes and its vascular lesions. Elsevier, New York, p 353-402

2. Epstein FM (1967) Hyperglycaemia - A risk factor in coronary heart disease. Circulation 36: 609-619

3. Stout RW, Vallance-Owen J (1969) Insulin and atheroma. Lancet I: $1078-1080$

4. Stout RW (1977) The relationship of abnormal circulating insulin levels to atherosclerosis. Atherosclerosis 27: 1-13

5. Stout RW (1979) Diabetes and atherosclerosis - The role of insulin. Diabetologia 16: 141-150

6. Richard JL, Ducimetiere P, Bonnaud G, Claude JR, Lellouch J, Schwartz D, Di Matteo J (1977) Incidence et évaluation du risque de maladie coronazienne. L'Etude Prospective Parisienne. Arch Mal Coeur 70: 531-537

7. Tran MH, Richard JL, Lellouch J (1973) La graisse d'une population masculine Française active de 4000 sujets de 46-52 ans. Pathol Biol 21: 747-754

8. Etienne G, Papin JP, Renault M (1963) Une méthode simple de dosage du cholesterol par voie automatique. Ann Biol Clin 21: $851-853$

9. Claude JR, Corre F (1968) Considerations pratiques sur le dosage semi automatique des triglycerides sériques par fluorometrie (méthode de Kessler et Lederer). Comparaison avec la méthode manuelle colorimétrique de Van Handel et Zilversmit. Ann Biol Clin 26: 451-454

10. Methodologie Technicon Auto-Analyser "N" 2a, 2ème ed. Décembre 1963

11. Rosselin G, Assan R, Yalow RS, Berson SA (1966) Separation of antibody bound and unbound peptide hormone labelled with iodine 131 by talcum powder and precipitates silica. Nature 212: 355-357 
12. Rosselin G, Claude JR, Eschwege E, Patois E, Warnet JM, Richard JL (1971) Diabetes survey, plasma insulin during $0-2 \mathrm{~h}$ oral glucose tolerance test systematically carried out in a professional group. Diabetologia 7: 34-45

13. Lellouch J, Rakotovao R (1976) L'estimation d'une courbe de risque comme une fonction de variables prédictives. I. Description de la méthode. Rev Epidem Santé Publ 24: 123-130

14. Ducimetiere P, Richard JL, Rakotovao R, Claude JR (1976) L'estimation d'une courbe de risque comme une fonction de variables prédictives. II. Application à l'analyse multivariate du risque de cardiopathies ischémiques dans une population masculine active d'âge moyen. Rev Epidem Santé Publ 24: 131-140

15. Epstein FM (1967) Some uses of prospective observations in the Tecumseh Community Health Study. Proc R Soc Med 60: $56-61$

16. Keen H, Jarrett RJ (1973) Macroangiopathy - Its prevalence in asymptomatic diabetes. Arch Metab Dis (Suppl) 2: 3-9

17. International Collaborative Group: Glycaemia and coronary heart disease: Introduction to a series of papers reporting findings from fifteen population studies. J Chronic Dis 32: 683-837

18. Fuller J, Mc Cartney P, Jarrett RJ, Keen H, Rose G, Shipley MJ, Hamilton PJS (1979) Hyperglycaemia and coronary heart disease: the Whitehall Study. J Chronic Dis 32: 721-728

19. Ducimetiere P, Eschwege E, Richard JL, Claude JR, Elgrishi I (1979) Relationship of glucose tolerance to prevalence of ECG abnormalities and to annual mortality from cardiovascular diseases: Results of the Paris Prospective Study. J Chronic Dis 32: 759-766

20. Pyorälä K, Nikkilä EA, Taskinen MR, Siltanen P, Punsar S (1979) Plasma insulin as coronary heart disease risk factor. Comm. to the 2nd Scientific Meeting of the Working Group on the Epidemiology and Prevention of Cardiovascular Diseases of the European Society of Cardiology, Dublin, 5-7 April 1979

21. Pyorälä K (1979) Relationship of glucose tolerance and plasma insulin to the incidence of coronary heart disease: Results from two population studies in Finland. Diabetes Care 2: 131-141

22. Welborn TA, Wearne K (1979) Coronary heart disease incidence and cardiovascular mortality in Busselton with refernce to glucose and insulin concentrations. Diabetes Care 2: 154-160

23. Peters N, Hales CN (1972) Plasma insulin concentrations after myocardial infarction. Lancet I: $1144-1145$

24. Nikkilä EA, Miettinen AA, Vesenne MR, Pelkonen R (1965) Plasma insulin in coronary heart disease. Lancet II: 508-511
25. Reaven GM, Olefsky JM (1978) Role of insulin resistance in the pathogenesis of hyperglycaemia. In: Katzen MM, Mahler RJ (eds) Diabetes, obesity, and vascular disease. Halsted Press, Washington, p 229-266

26. Perley M, Kipnis DM (1966) Plasma insulin responses to glucose and tolbutamide of normal weight and obese diabetic and non diabetic subjects. Diabetes 15: 867-873

27. Seltzer NJ, Allen W, Herron AL, Brennan MT (1967) Insulin secretion in response to glycemic stimulus: relation of delayed initial release to carbohydrate intolerance in mild diabetes mellitus. J Clin Invest 46: 1954-1962

28. Sorge F, Schwartzkopff W, Neuhaus GA (1976) Insulin response to oral glucose in patients with a previous myocardial infarction and in patients with peripheral vascular disease. Diabetes 25: 586-594

29. Santen RJ, Willis PW, Fajans SS (1972) Atherosclerosis in diabetes mellitus. Correlations with serum lipids levels, adiposity and serum insulin level. Arch Intern Med 1.30: 833-843

30. Heyden S (1975) The problem with triglycerides. Nutr Metab 18: $1-3$

31. Gordon T, Castelli WP, Hjortland MC, Kannel WB, Dawber TR (1977) Diabetes, blood lipids and the role of obesity in coronary heart disease risk for women. The Framingham Study. Ann Intern Med 87: 393-397

32. Wilhelmsen L, Vedel H, Tibblin G (1973) Multivariate analysis of risk factors for coronary heart disease. Circulation 48 : 950-954

33. Carlson LA, Bottiger LE (1972) Ischemic heart diseases in relation to fasting values of plasma triglycerides and cholesterol. Lancet I: 863-867

34. Blackburn $H$ (1974) Progress in the epidemiology and prevention of coronary heart disease. In: Yu P, Goodwin J (eds) Progress in cardiology. Lea and Febiger, Philadelphia, p 1-15

Received: June 22, 1979, and in revised form: March 21, 1980

\author{
P. Ducimetiere \\ 169 INSERM \\ 16 bis, avenue PV Couturier \\ F-94800 Villejuif \\ France
}

